Full Length Article

\title{
Thermodynamic re-assessment of the Zn-P binary system
}

\author{
Masoomeh Ghasemi ${ }^{\text {a,b,*, E. Stutz }}{ }^{\text {b }}$, S. Escobar Steinvall ${ }^{\text {b }}$, M. Zamani ${ }^{\text {b }}$, A. Fontcuberta i Morral ${ }^{\text {b }}$ \\ ${ }^{\text {a }}$ Physics Department, Persian Gulf University, Booshehr, Iran \\ ${ }^{\mathrm{b}}$ Laboratoire des Matériaux Semiconducteurs, Institut des Matériaux, Ecole Polytechnique Fédérale de Lausanne, Lausanne CH-1015, Switzerland
}

\section{A R T I C L E I N F O}

\section{Keywords:}

Phase diagram calculations

CALPHAD

Semiconductors

Nanostructures

$\mathrm{Zn}-\mathrm{P}$

\begin{abstract}
A B S T R A C T
Thermodynamic phase diagrams are the cornerstones to develop synthesis of new materials. Zinc phosphide has evolved into a prospective semiconductor for next generation solar cells, thanks to its abundance and functional properties. Here we derive an optimized Zn-P binary diagram, and compare it to two previously available assessments. We solve some of the artefacts and clarify the methodology to obtain the Gibbs free energy, reaching an accurate description of the phases. This work is important for the synthesis of zinc-phosphide in the form of thin film and nanostructures.
\end{abstract}

\section{Introduction}

Low-cost and efficient semiconductors are timely for applications in solar power conversion. Due to its suitable optoelectronic proprieties, zinc phosphide $\left(\mathrm{Zn}_{3} \mathrm{P}_{2}\right)$ is a suitable material. The direct bandgap of this material has been commonly quoted at around $1.5 \mathrm{eV}$, with an indirect one in the range $1.3-1.4 \mathrm{eV}$, however, there is still some uncertainty regarding the exact energies [1-4]. It also possesses a long minoritycarrier diffusion length $(>7 \mu \mathrm{m})[1]$ as well as strong light absorption in the visible range [5]. Moreover, $\mathrm{Zn}$ and $\mathrm{P}$ are extracted in a relatively low-cost manner. Both elements are also considered to be abundant in the earth crust.

Thin films [6-9] and one-dimensional nanostructures [10,11] of $\mathrm{Zn}_{3} \mathrm{P}_{2}$ have been synthesized. To better understand the growth mechanism of $\mathrm{Zn}_{3} \mathrm{P}_{2}$ structures, and to investigate the feasible integration with other materials, knowledge regarding the phase equilibria of this system is imperative.

In this work, we have re-optimized the phase diagram of the $\mathrm{Zn}-$ $P$ system using the CALculation of PHAse Diagram (CALPHAD) method [12]. The Zn-P system has been previously assessed by Tu et al. [13] and Liu et al. [14]. These previous assessments have deficiencies that we revise in this work. This will then be the base for obtaining phase diagrams based on the $\mathrm{Zn}-\mathrm{P}$ system and that can be used for the growth of nanowires, such as the In-Zn-P or Ga-Zn-P. In addition, we also compare the modeling of the excess Gibbs energy of the liquid phase as a function of temperature in three different ways: using the subregular linear, the Kaptay [15] and the LET functions [16]. The linear function usually gives rise to the formation of artificial inverted miscibility gaps at high temperatures. To prevent such artifacts, Kaptay [15] introduced a semi-empirical exponential equation for the interaction energy of the solution phases. Another alternative is the multiplier function, the socalled LET function, proposed by Liang et al. [16].

The structure of the manuscript is as follows. In Section 2, a general description of the CALPHAD methodology is given which is accompanied by the explanation of the thermodynamic models in Appendix A. In Section 3, a literature survey on the crystal structure, phase diagram and thermodynamic data of the Zn-P system is presented. In Section 4, the optimized thermodynamic description of the Zn-P system with which the diagrams are calculated is presented. Finally, a discussion on the models of the excess Gibbs energy is given.

\section{Thermodynamic modeling}

We have used the well-known semi-empirical CALPHAD method [12] to model the $\mathrm{Zn}-\mathrm{P}$ binary system. In this method, the Gibbs energies of all phases in a thermodynamic system are derived based on the available experimental data and theoretical calculations. The experimental inputs are multiple and include the thermodynamic quantities, phase diagram data such as melting or sublimation temperatures and crystallographic information of the solid phases. Ab-initio calculations of total energies can also serve as inputs in the absence of experimental measurements.

A phase diagram is constructed by calculating the Gibbs energies of different phases at constant $T$ and $P$ and finding stable phases by minimizing the total Gibbs energy of the system. The Gibbs energy, $G$, is a function of temperature $(T)$, pressure $(P)$, and composition $(x)$. Several model parameters are introduced to describe the Gibbs energy of the phases. These parameters are adjusted to fit the experimental data. As a result, a self-consistent database composed of Gibbs energy functions for the materials system is obtained. This data allows us to derive the

\footnotetext{
* Corresponding author at: Physics Department, Persian Gulf University, Booshehr, Iran.

E-mail address: gh.phys@gmail.com (M. Ghasemi).
} 
phase diagrams and other thermodynamic properties of the system. The other thermodynamic functions that can be derived from $G$ include:

Entropy:

$-S=\left(\frac{\partial G}{\partial T}\right)_{P, n_{i}}$

Enthalpy:

$H=G-T\left(\frac{\partial G}{\partial T}\right)_{P}$

Chemical potential:

$\mu_{j}=\left(\frac{\partial G}{\partial n_{j}}\right)_{T, P, n_{i \neq j}}$

Heat capacity:

$C_{p}=-T\left(\frac{\partial^{2} G}{\partial T^{2}}\right)_{P}$

where $n_{i}$ is the composition of component $i$.

The details for Gibbs energy models for the Zn-P system are found in Appendix A.

\section{Literature data}

\subsection{Crystal structure and phase diagram data}

The available phase diagram data for the Zn-P system range from 0 to 66 at.\% P [34-36]. Dutkiewicz was the first to evaluate the Zn-P phase diagram [37]. In addition to the terminal phases: (Zn) and (P) and the liquid phase, there are two stoichiometric compounds in this system, $\mathrm{Zn}_{3} \mathrm{P}_{2}$ and $\mathrm{ZnP}_{2}$. Both compounds melt congruently.

Ugai et al. [34] investigated the $\mathrm{Zn}-\mathrm{Zn}_{3} \mathrm{P}_{2}$ system by employing microstructural and thermal analysis and the microhardness method in the composition range of 0-30 wt.\% P. Berak and Pruchnik studied the composition range of 0-66 at\% $\mathrm{P}$ using thermal, microscopic and X-ray analysis. Schneider and Krumnacker used differential thermal analysis in the composition range of $0-30$ Mass $\% \mathrm{P}$. The same experimental data as of Ref. [36] is given in the work of John et al. [38] without mentioning the reference. We have digitized the datapoints in the phase diagram from [34-36] shown in Fig. 1(a) and (b). For the modeling, we have used liquidus temperatures of Ref. [36] up to 47 at $\%$ P and those of Ref.[35] between 47 and 65 at\% $P$.

There are two eutectic reactions in this system. The composition of the $\mathrm{Zn}$-rich eutectic is not known. Ugai et al. [34] suggested a value of 2.5 at\% $\mathrm{P}$ which does not agree with the liquidus data of $[35,36]$. A value of 0.66 at $\%$ P was calculated by authors of Refs. [35,36] using a simple thermodynamic approximation [37]. The composition of the eutectic reaction between $\beta \mathrm{Zn}_{3} \mathrm{P}_{2}$ and $\alpha \mathrm{ZnP}_{2}$ of 55 at $\% \mathrm{P}$ was reported in [35]. The eutectic temperatures measured by authors of Refs. [35,36] are $980{ }^{\circ} \mathrm{C}$ and $950{ }^{\circ} \mathrm{C}$, respectively. The values reported in Ref. [35] have been taken into account in the current work (see Table 4).

Both intermetallic compounds have a low- and high-temperature polymorph, called $\alpha$ and $\beta$ in the present manuscript. The $\alpha \rightarrow \beta$ transformation of this phase occurs at $850^{\circ} \mathrm{C}$, while the melting of $\beta Z n_{3} P_{2}$ occurs at $1160{ }^{\circ} \mathrm{C}$ and according to Schneider and Krumnacker [36]. The measured melting and transformation temperatures by Berak and Pruchnik [35] are higher than those reported in [36] (see Table 4) which may be due to pressure effects as mentioned by Pistorius et al. [17]. The solidsolid transition of $\mathrm{Zn}_{3} \mathrm{P}_{2}$ has been measured in [17] at pressures up to $38 \mathrm{kbar}$. At about $10 \mathrm{kbar}$, a sharp peak in the slope of the temperaturepressure curve was observed. Two interpretations were suggested to explain this observation. The first explanation was that the peak represents a triple point at which a third polymorph of $\mathrm{Zn}_{3} \mathrm{P}_{2}$ forms. It was also suggested that the peak occurs due to decomposition below $10 \mathrm{kbar}$, which is seen as the pressure was initially raised to $10 \mathrm{kbar}$ to prevent decomposition during experiments. The first assumption leads to an $\alpha \rightarrow \beta$ (a)

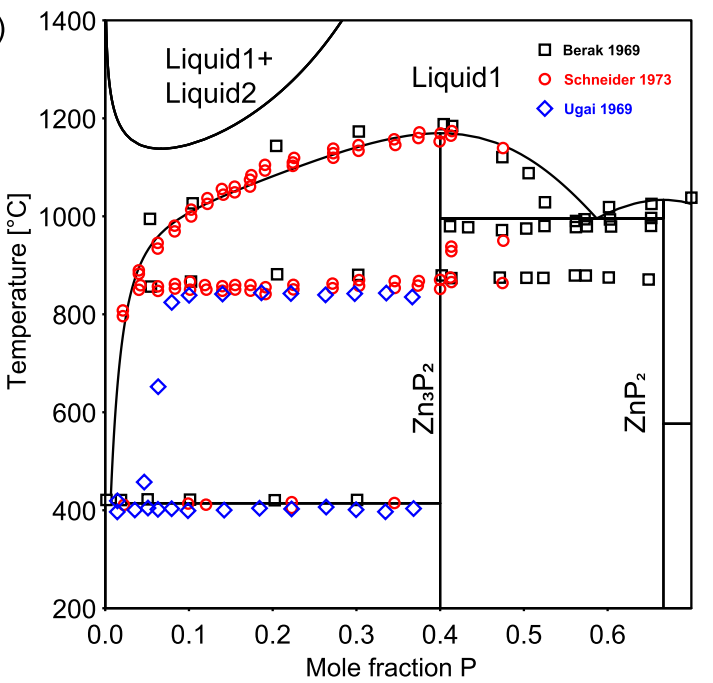

(b)

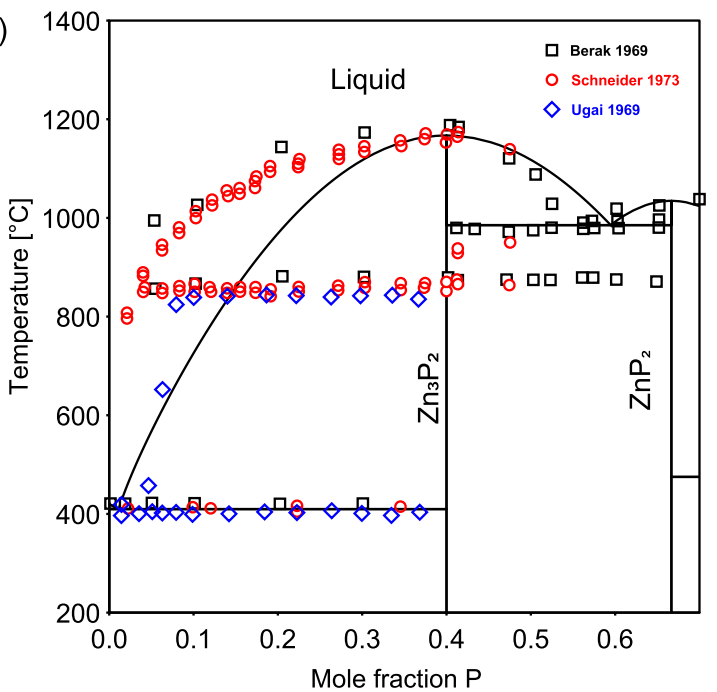

(c)

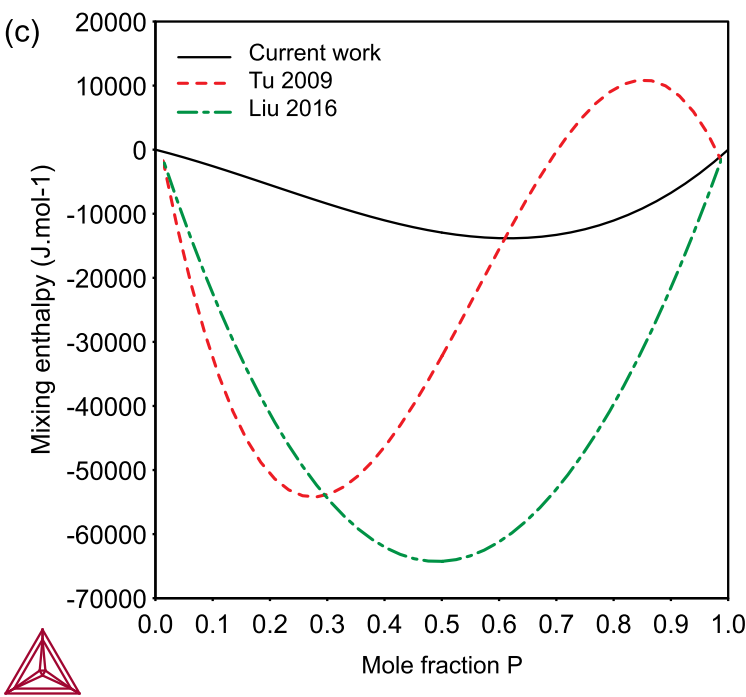

Fig. 1. The calculated phase diagram of the Zn-P system from parameters optimized by (a) Tu et al. [13] and (b) Liu et al. [14]. The experimental data of [34-36] are superimposed on the diagrams. (c) The calculated enthlpy of mixing in the liquid phase from parameters optimized in the current work (solid curve), [13] (dashed curve) and [14] (dashed-dotted curve). 
Table 1

Crystal structure of phases in the Zn-P system.

\begin{tabular}{|c|c|c|c|c|c|c|}
\hline Phase & at. $\% \mathrm{P}$ & Pearson symbol & Space group & Strukturberich designation & Prototype & Ref. \\
\hline $\mathrm{Zn}$ & 0 & hP2 & $\mathrm{P}_{3} / \mathrm{mmc}$ & A3 & $\mathrm{Mg}$ & \\
\hline$\beta \mathrm{Zn}_{3} \mathrm{P}_{2}$ & 40 & $\mathrm{cF} 12$ & Fm-3m & $\mathrm{C} 1$ & $\mathrm{CaF}_{2}$ & [17] \\
\hline$\alpha \mathrm{Zn}_{3} \mathrm{P}_{2}$ & 40 & tP40 & $\mathrm{P}_{2} / \mathrm{nmc}$ & $\mathrm{D}_{9}$ & $\mathrm{Zn}_{3} \mathrm{P}_{2}$ & [18] \\
\hline$\beta \mathrm{ZnP}_{2}$ & 66.6 & $\mathrm{mP} 24$ & $\mathrm{P} 2{ }_{1} / \mathrm{c}$ & $\ldots$ & $\mathrm{As}_{2} \mathrm{Zn}$ & [19] \\
\hline$\alpha \mathrm{ZnP}_{2}$ & 66.6 & tP24 & $\mathrm{P} 4{ }_{1} 2_{1} 2$ & $\ldots$ & $\mathrm{ZnP}_{2}$ & [19] \\
\hline$\gamma \mathrm{ZnP}_{2}$ & 66.6 & Cubic & $\ldots$ & $\ldots$ & $\ldots$ & {$[20]$} \\
\hline $\mathrm{ZnP}_{4}$ & 80 & Tetragonal & $\mathrm{P} 4{ }_{1} 2_{1} 2$ & $\ldots$ & $\ldots$ & {$[21]$} \\
\hline $\mathrm{Zn}_{7} \mathrm{P}_{10}$ & 58.8 & Orthorhombic & Fdd2 & $\ldots$ & $\ldots$ & {$[21]$} \\
\hline P(black) & 100 & oC8 & Cmca & $\ldots$ & $\ldots$ & \\
\hline $\mathrm{P}$ (white) & 100 & aP24 & P-1 & $\ldots$ & $\ldots$ & {$[22,23]$} \\
\hline P(red) & 100 & Cubic & $\ldots$ & $\ldots$ & $\ldots$ & \\
\hline
\end{tabular}

Table 2

Thermodynamic properties.

\begin{tabular}{|c|c|c|c|c|}
\hline Compound & $\Delta_{f} G_{298}^{\circ} \mathrm{J} / \mathrm{mol}$ & $\Delta_{f} H_{298}^{\circ} \mathrm{J} / \mathrm{mol}$ & Comment & Ref. \\
\hline \multirow{10}{*}{$\mathrm{Zn}_{3} \mathrm{P}_{2}$} & $-158,707$ & $-151,839$ & Assessed & {$[14]$} \\
\hline & $-168,810$ & $-181,780$ & Assessed & [13] \\
\hline & $-180,100 \pm 13,000$ & $-173,200 \pm 10,400$ & Calc. from emf data & {$[24]$} \\
\hline & & $-165,268 \pm 20,920$ & Vapor pressure data & {$[25]$} \\
\hline & & $-198,740 \pm 23,012$ & Vapor pressure & {$[26]$} \\
\hline & & $-230,245 \pm 20,920$ & Calorimetry & {$[27]^{\mathrm{a}}$} \\
\hline & & $-223,426$ & Calorimetry & {$[28]^{\mathrm{a}}$} \\
\hline & & $-410,032$ & Calorimetry & {$[29]^{\mathrm{a}}$} \\
\hline & & $-410,032 \pm 12,552$ & Calorimetry & {$[30]^{\mathrm{a}}$} \\
\hline & $-184,175$ & $-165,610$ & This work & Des. 1 \\
\hline \multirow[t]{9}{*}{$\mathrm{ZnP}_{2}$} & $-118,032$ & -92928.2 & Assessed & {$[14]$} \\
\hline & $-126,200$ & $-126,850$ & Assessed & {$[13]$} \\
\hline & $-127,400 \pm 7500$ & $-122,900 \pm 5500$ & Calc. from emf data & {$[24]$} \\
\hline & & $-85,354 \pm 8370$ & & [31] \\
\hline & & $-122,591 \pm 7112$ & & {$[25]^{\mathrm{b}}$} \\
\hline & & $-92,885$ & & {$[32]^{\mathrm{b}}$} \\
\hline & & $-167,369 \pm 14,644$ & & {$[33]^{\mathrm{b}}$} \\
\hline & & $-99,998 \pm 7113$ & & {$[31]^{c}$} \\
\hline & $-121,188$ & $-121,308$ & This work & Des. 1 \\
\hline
\end{tabular}

a Due to inaccessibility to the original reference, these values are taken from [26].

b These values are calculated based on the measured data in referred papers and reported by Alikhanyan et al. [31].

c This value is recalculated from experimental data of [33] according to Eq. (7) in [31].

transformation temperature of $845^{\circ} \mathrm{C}$ and the extrapolated temperature based on the latter interpretation is $875{ }^{\circ} \mathrm{C}$. We have accepted the values from Schneider and Krumnacker [36] for the melting point and polymorphic transitions of $\mathrm{Zn}_{3} \mathrm{P}_{2}$. Furthermore, $\beta \mathrm{ZnP}_{2}$ melts at $1040{ }^{\circ} \mathrm{C}$ and undergoes the $\alpha \rightarrow \beta$ transformation at $990{ }^{\circ} \mathrm{C}$ as reported by Berak and Pruchnik [35].

Lazarev et al. [32] investigated the deviation from stoichiometry of $\mathrm{Zn}_{3} \mathrm{P}_{2}$ by constructing the $\mathrm{p}-\mathrm{T}$ projections of the phase diagram. The break points of the unsaturated vapor curves are representative of changes in the phase state of a system. They determined that the deviation from stoichiometry in $\mathrm{Zn}_{3} \mathrm{P}_{2}$ is $0.009-0.012$ at $\% \mathrm{P}$ at $785-820{ }^{\circ} \mathrm{C}$. As the homogeneity region is less than 1 at $\%$, it has not been taken into account in the assessment.

The crystal structure of the phases in the $\mathrm{Zn}-\mathrm{P}$ system are listed in Table 1 . In our calculations, $\mathrm{Zn}$ with $\mathrm{P}_{3} / \mathrm{mmc}$ and $\mathrm{P}$ (white) are assumed as standard states $[39,40] . \alpha \mathrm{Zn}_{3} \mathrm{P}_{2}$ is tetragonal [18] and the $\beta$ polymorph has a cubic structure [17]. The low- and high-temperature polymorphs of $\mathrm{ZnP}_{2}$ exhibit a tetragonal [19] and monoclinic [19] structures, respectively. High-pressure phases have also been identified for this system. $\gamma \mathrm{ZnP}_{2}$ is a metastable modification of $\mathrm{ZnP}_{2}$ with an orthorhombic structure [20,21]. In addition, $\mathrm{ZnP}_{4}$ (tetragonal) and $\mathrm{Zn}_{7} \mathrm{P}_{10}$ were synthesized at 4-5 GPa by Trukhan et al. [21]. We have not considered the high-pressure phases in the present assessment.

\subsection{Thermodynamic data}

The thermodynamic properties of $\mathrm{Zn}_{3} \mathrm{P}_{2}$ and $\mathrm{ZnP}_{2}$ were studied by the authors in Refs. [24-30] and in Refs. [24,25,32,33], respec- tively. Table 2 summarizes the reported values in the mentioned references.

Sirota et al. [24] determined the heats, free energies and entropies of the formation of $\mathrm{Zn}_{3} \mathrm{P}_{2}$ and $\mathrm{ZnP}_{2}$ compounds from measurements of the electromotive forces (emf) in galvanic cells. Their reported values were referenced to black phosphorus. Schoonmaker et al. [25] studied the sublimation of $\mathrm{Zn}_{3} \mathrm{P}_{2}$ by means of torsion effusion, torsion surface vaporization and mass spectrometry methods in the temperature range $347-547{ }^{\circ} \mathrm{C}$. They estimated the standard heat of formation of $\mathrm{Zn}_{3} \mathrm{P}_{2}$ at room temperature from red phosphorus and crystalline zinc. Valov and Ushakova [26] investigated the dissociation pressure of $\mathrm{Zn}_{3} \mathrm{P}_{2}$ in the temperature range of $617-1067{ }^{\circ} \mathrm{C}$ and determined the vapor pressure. They extracted the enthalpy and entropy of formation from red phosphorus and solid zinc at room temperature. Unfortunately, we did not have access to Refs. [27-30] and the values in Table 2 were taken from [26].

Alikhanyan et al. [31] studied the sublimation of $\mathrm{ZnP}_{2}$ using a Knudsen effusion cell and a Bourdon gauge for different temperature regimes. They estimated the enthalpy of formation of $\mathrm{ZnP}_{2}$ from red phosphorus and solid zinc based on their measurements, and also recalculated this quantity from the data reported in Ref. [25,32,33]. For the present assessment, we have used the estimated formation enthalpy of compounds from the measured data of Schoonmaker et al. [25].

The temperature dependent heat capacity of $\alpha \mathrm{ZnP}_{2}$ was measured by Sheleg et al. [41] between 6 and $400 \mathrm{~K}$ by means of the vacuum adiabatic calorimeter method. This set of data was taken into account in the modeling. Sirota et al. [24] found approximate expressions for the temperature dependence of the heat capacity of the $\mathrm{Zn}_{3} \mathrm{P}_{2}$ and $\mathrm{ZnP}_{2}$ compounds 
from emf measurements between 300-1000 K. Low-temperature heat capacity of $\alpha \mathrm{Zn}_{3} \mathrm{P}_{2}$ single crystals was measured by Bartkowski et al. [42] in the temperature range of 3-20 K. However, the values are not tabulated and due to the poor quality of corresponding figure in the paper, we were not able to use the heat capacity data of $\alpha \mathrm{Zn}_{3} \mathrm{P}_{2}$.

\section{Results and discussion}

We performed the re-optimization of the Zn-P system using the PARROT module [43] of the academic version of Thermo-Calc [44]. The motivations for the current work were multiple and include (i) to clarify the description of the liquid phase so as to prevent the appearance of the inverted miscibility gap, (ii) to correctly implement the exponential model of Kaptay, (iii) to show a comparison of the linear, exponential and LET models for the description of the excess energy parameters of the liquid phase, (iv) to model the polymorphic transformation of intermetallic phases, and (v) to use the available temperature-dependent heat capacity data for $\alpha \mathrm{ZnP}_{2}$.

There are two previous assessments of this system performed by $\mathrm{Tu}$ et al. [13] and Liu et al. [14]. The former was performed in connection to the assessment of the Al-Zn-P ternary system and the latter dealt with the Si-Zn-P system. The calculated phase diagram using the optimized parameters by $\mathrm{Tu}$ et al. [13] shows an inverted miscibility gap in the liquid phase appearing at about $1140{ }^{\circ} \mathrm{C}$ with no maximum temperature (Fig. 1(a)). Moreover, the polymorphic transformations of the intermtallic compounds were not modeled. Liu et al. [14] modeled the liquid phase using the exponential model suggested by Kaptay [15] to prevent the appearance of the artificial miscibility gap. It is noteworthy to declare that the $\tau$ parameter optimized by Liu et al. [14] is negative. However, according to [15], $\tau$ must be positive, otherwise the excess Gibbs energy would not equal zero at high temperatures. The calculated phase diagram using their parameters (Fig. 1(b)) shows that the fit to the liquidus data is not satisfactory. In addition, this assessment also lacks a description of polymorphic transformations.

First, we assessed the system using the linear function of the interaction parameter (Description 1, Eq. (A.4)). Next, we fixed the $a_{0}$ coefficient of Eq. (A.2) for the intermetallic phases and optimized the liquidus coefficients via the exponential (Description 2, Eq. (A.5)) and LET models (Description 3, Eq. (A.7)). Because there was no experimental data between 66 and 100 at\% P, no attempt was made to obtain a thermodynamic description for P-rich composition range. Table 3 lists the optimized parameters of the $\mathrm{Zn}-\mathrm{P}$ system.

The mixing enthalpy in the liquid phase is calculated from parameters optimized by Tu et al. [13] and Liu et al. [14] in Fig. 1(c) and compared to the assessed parameters in this work. In the absence of experimental data on the mixing enthalpy, one cannot judge which description is correct. However, too high values of the $a_{i}$ and $b_{i}$ coefficients of the interaction parameter may lead to an artificial miscibility gap and an incorrect performance when extrapolating to higher order systems.

Fig. 2 shows calculated phase diagrams from Descriptions 1-3. In Fig. 2(a), the diagram is calculated by parameters optimized for the linear model of the liquid interaction parameter. A very good fit is observed with the selected experimental data of [34-36] (explained in Section 3) which are superimposed on the diagram. A zoomed view of the diagram

Table 3

Phase names, functions, models and parameters of the Gibbs energy equations developed in the present work.

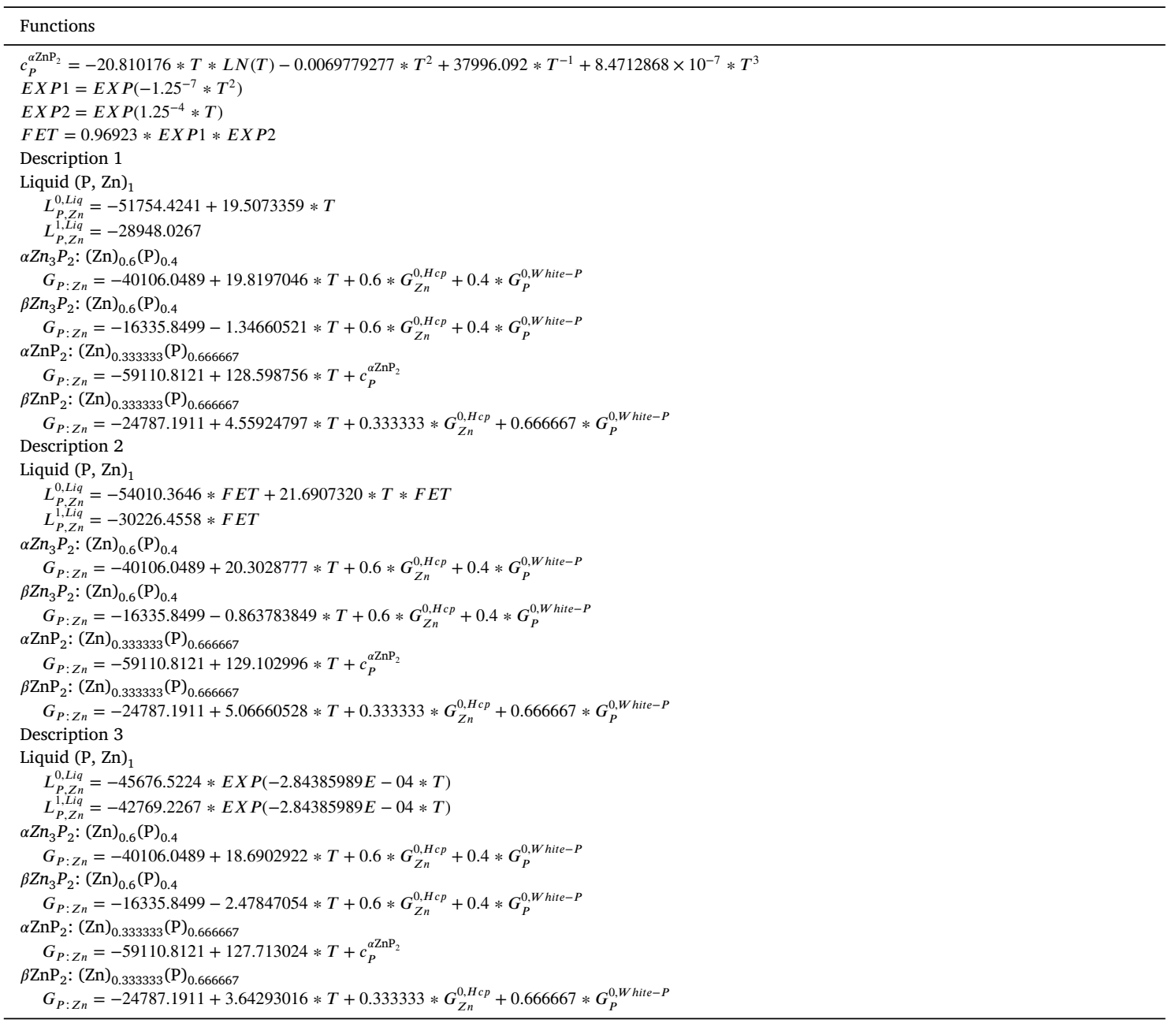


(a)

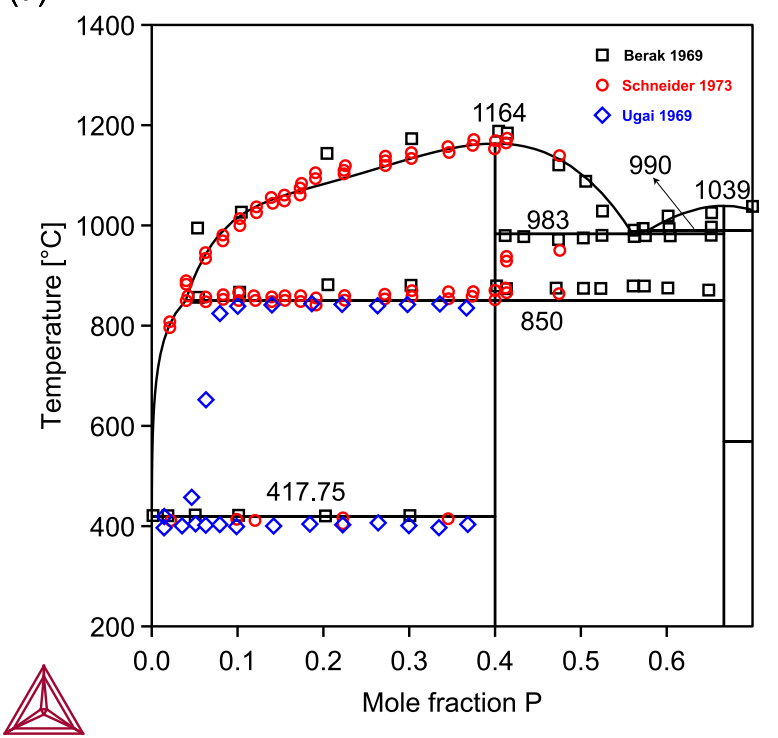

(c)

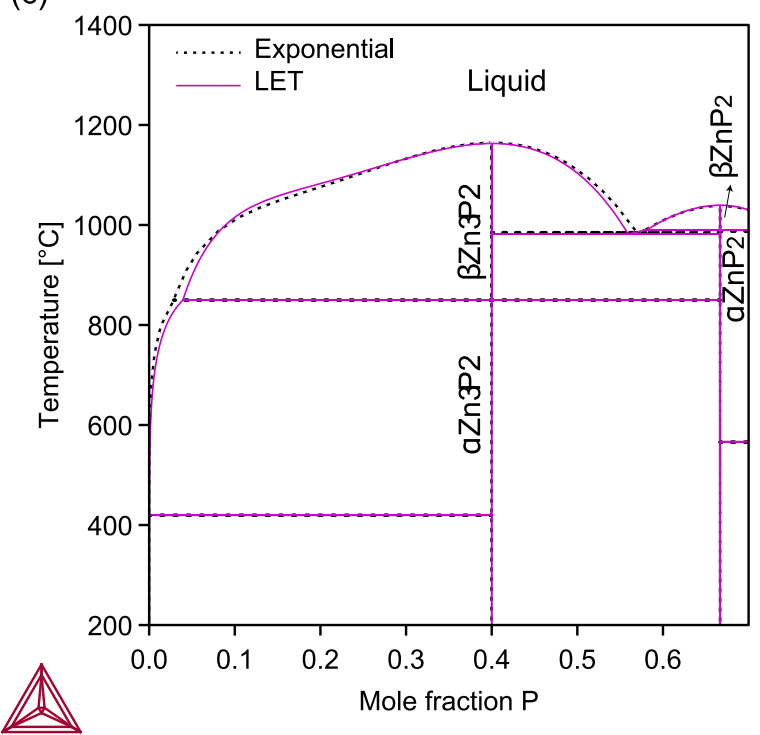

(b)

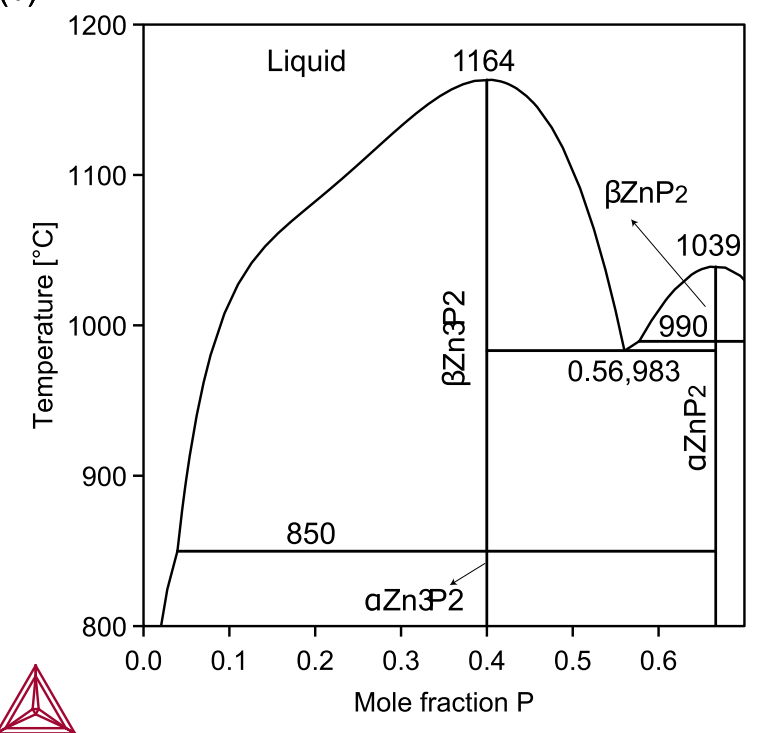

(d)

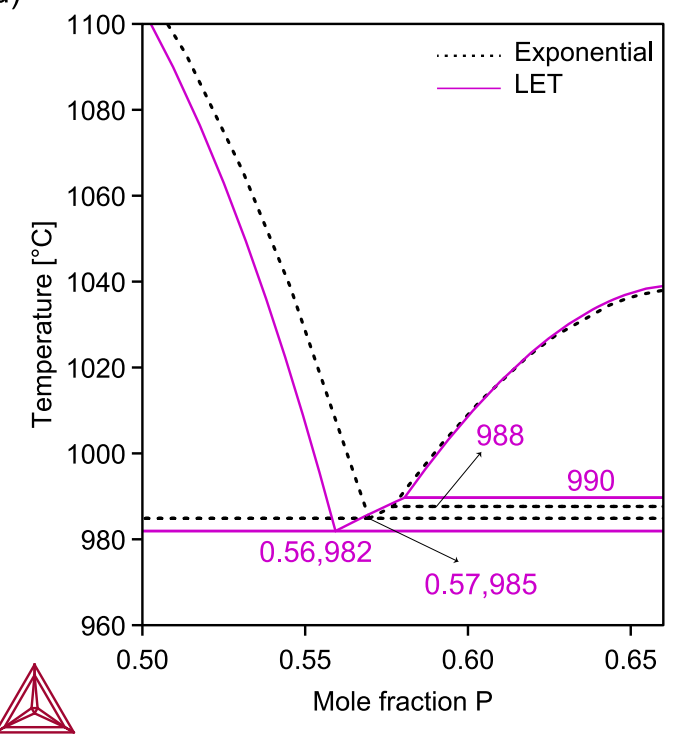

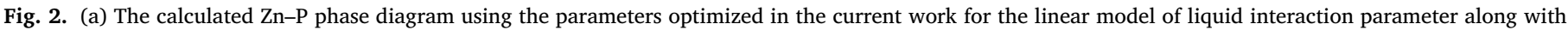

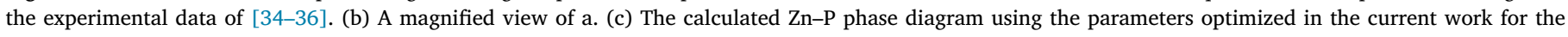
exponential (dotted-line) and LET model (solid line) of liquid interaction parameter. (d) A magnified view of c.

is shown in Fig. 2(b) in which the composition and temperatures of the invariant reactions are marked. A list of invariant reactions with calculated and measured compositions and temperatures are given in Table 4.

The calculated phase diagrams using the exponential and the LET model of the liquid interaction parameter (Descriptions 2 and 3, respectively) are shown in Fig. 2(c). The characteristic points calculated using Description 3 are very close to Description 1 (see Table 4), while Description 2 results in slightly different values as depicted in Fig. 2(d). However, all three descriptions are in a satisfactory agreement with the experimental values.

The excess Gibbs energy, entropy, mixing enthalpy and heat capacity of the liquid phase at 40 at $\% \mathrm{P}$ are calculated using the linear, the exponential and the LET functions and are shown in Fig. 3(a)-(d). The linear model as explained by Chen et al. [45] is prone to exhibiting high temperature arefacts. Though this behavior is not observed for the current assessment until $6000 \mathrm{~K}$, we had to add artificial experiments at high temperatures for the liquid phase to prevent the appearance of the inverted miscibility gap. The form of the suggested functions by Kaptay [15] and Liang et al. [16] avoids such high temperature artefacts as the excess Gibbs energy, entropy, mixing enthalpy and heat capacity tend to zero at high temperatures $[16,46]$.

As seen from Fig. 3, at very high temperatures, the exponential and LET models work similarly and both tend to zero. While a closer fit to the experimental data was obtained using the LET model, it provides a more negative excess Gibbs energy for the liquid when extrapolated to $0 \mathrm{~K}$, compared to the exponential model. All in all, both the exponential and LET functions describe the actual phase diagram details similarly, with no low- or high-temperature artefact. However, the T-dependency of the LET function is less probable to be observed experimentally than the exponential model, thus in absence of experimental data for the liquid phase, the simpler model (the exponential model) may be encouraged.

In conclusion, we have re-optimized the thermodynamic description of the Zn-P binary system. The appearance of the inverted miscibility 
Table 4

Invariant reactions in Zn-P system. "Des. 1", “Des. 2" and "Des. 3" stand for Description 1 (Eq. (A.4)), Description 2 (Eq. (A.5)) and Description 3 (Eq. (A.7)).

\begin{tabular}{|c|c|c|c|c|c|c|}
\hline \multirow{2}{*}{$\begin{array}{l}\text { Reactions } \\
L \rightarrow(Z n)+\alpha Z n_{3} P_{2}\end{array}$} & \multicolumn{3}{|c|}{ Compositions of respective phase, at $\% \mathrm{P}$} & \multirow{2}{*}{$\begin{array}{l}\text { Reaction type } \\
\text { Eutectic }\end{array}$} & \multirow{2}{*}{$\begin{array}{l}\text { Temperature, }{ }^{\circ} \mathrm{C} \\
416\end{array}$} & \multirow{2}{*}{$\frac{\text { Ref. }}{[36]}$} \\
\hline & 0.66 & 04 & & & & \\
\hline & 0.66 & & & & 419 & {$[35]$} \\
\hline & 2.5 & & & & 401 & {$[34]$} \\
\hline & 0.34 & & & & 417.75 & Des. 1 \\
\hline & 0.07 & & & & 419.15 & Des. 2 \\
\hline & 0.36 & & & & 417.65 & Des. 3 \\
\hline \multirow[t]{6}{*}{$\alpha Z n_{3} P_{2} \rightarrow \beta Z n_{3} P_{2}$} & & 40 & & Polymorphic & 850 & {$[36]$} \\
\hline & & & & & 845 & {$[17]$} \\
\hline & & & & & 880 & {$[35]$} \\
\hline & & & & & 850 & Des. 1 \\
\hline & & & & & 850 & Des. 2 \\
\hline & & & & & 850 & Des. 3 \\
\hline \multirow[t]{6}{*}{$L \rightarrow \beta Z n_{3} P_{2}$} & & 40 & & Congruent & 1160 & {$[36]$} \\
\hline & & & & & 1193 & {$[35]$} \\
\hline & & & & & 840 & {$[34]$} \\
\hline & & & & & 1164 & Des. 1 \\
\hline & & & & & 1165 & Des. 2 \\
\hline & & & & & 1163 & Des. 3 \\
\hline \multirow[t]{5}{*}{$L \rightarrow \beta Z n_{3} P_{2}+\alpha \mathrm{ZnP}_{2}$} & 55 & 40 & 66.6 & Eutectic & 980 & [35] \\
\hline & & & & & 950 & {$[36]$} \\
\hline & 56 & 40 & 66.6 & & 983 & Des. 1 \\
\hline & 57 & 40 & 66.6 & & 985 & Des. 2 \\
\hline & 56 & 40 & 66.6 & & 982 & Des. 3 \\
\hline \multirow[t]{4}{*}{$\alpha \mathrm{ZnP}_{2} \rightarrow \beta \mathrm{ZnP}_{2}$} & & 66.6 & & Polymorphic & 990 & {$[35]$} \\
\hline & & & & & 990 & Des. 1 \\
\hline & & & & & 988 & Des. 2 \\
\hline & & & & & 990 & Des. 3 \\
\hline \multirow[t]{4}{*}{$L \rightarrow \beta \mathrm{ZnP}_{2}$} & & 66.6 & & Congruent & 1040 & [35] \\
\hline & & & & & 1039 & Des. 1 \\
\hline & & & & & 1038 & Des. 2 \\
\hline & & & & & 1040 & Des. 3 \\
\hline
\end{tabular}
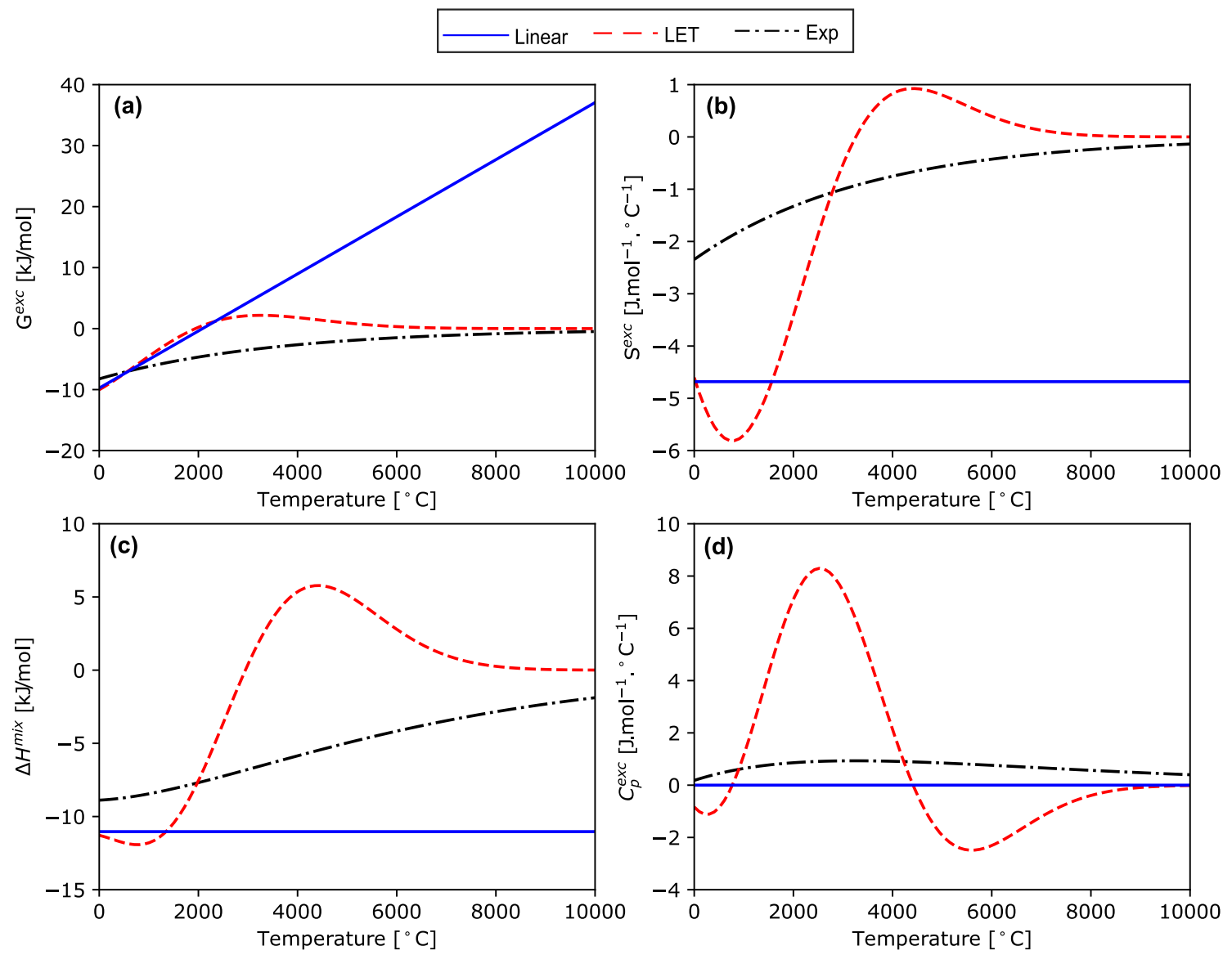

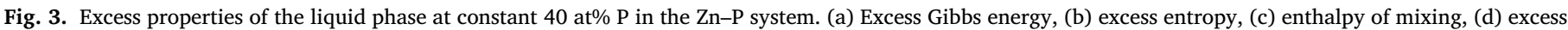
heat capacity. Solid, dashed and dotted-dashed curves denote the "linear" (Eq. (A.4)), "exponential" (Eq. (A.5)) and "LET" (Eq. (A.7)) functions, respectively. 
gap in the liquid phase is avoided, the polymorphic transformations are included in the modeling and the heat capacity data of the $\alpha \mathrm{ZnP}_{2}$ is taken into account. We have used three different models for the interaction parameter of the liquid phase: the linear, the exponential and the LET functions. The phase diagram features obtained from these models are compared. All assessments are in a close agreement to the available experimental data.

\section{Declaration of interests}

The authors declare that they have no known competing financial interests or personal relationships that could have appeared to influence the work reported in this paper.

\section{Acknowledgments}

M. Ghasemi is grateful to Alan Dinsdale, Malin Selleby, Rainer Schmid-Fetzer, Goerge Kaptay, Setareh Zomorodpoosh for fruitful discussions during the course of the current work. E. Stutz, S. Escobar Steinvall, M. Zamani and A. Fontcuberta i Morral thank SNF through the consolidator grant BSCGIO - 157705.

\section{Appendix A. Thermodynamic equations}

The molar Gibbs energy, $G_{m}$, of an elemental phase $\theta$ is described by a function of temperature as:

$$
\begin{aligned}
G_{m}^{\theta}-H^{\mathrm{SER}}= & a_{0}+a_{1} T+a_{2} T \ln (T)+a_{3} T^{2} \\
& +a_{4} T^{-1}+a_{5} T^{3}+\cdots
\end{aligned}
$$

where $H^{\text {SER }}$ is the molar enthalpy of the element at $298.15 \mathrm{~K}$ and 1 bar in its standard element reference (SER) state, which is white phosphorus for $\mathrm{P}$ and hcp for $\mathrm{Zn}$. Even though red phophorus is the more stable form of $\mathrm{P}$, it is recommended to use white- $\mathrm{P}$ as the reference phase [47]. The $a_{i}$ coefficients are taken from the SGTE (Scientific Group Thermodata Europe) thermodynamic database [47].

The Gibbs energy of $\alpha \mathrm{ZnP}_{2}$ has the same form as Eq. (A.1) because data on heat capacity measurements as a function of temperature is available for this compound. For $\beta \mathrm{ZnP}_{2}, \alpha \mathrm{Zn}_{3} \mathrm{P}_{2}$ and $\beta \mathrm{Zn}_{3} \mathrm{P}_{2}$, the heat capacity is the weighted average of the heat capacities of the end members. Hence, only a linear temperature dependency of the Gibbs energy of formation from the constituent elements is taken into account based on the Kopp-Neumann rule:

$G_{m}^{\theta}=a_{0}+a_{1} T+\sum b_{i} G_{i}^{\theta}$

where $a_{0}$ and $a_{1}$ are the coefficients to be optimized. The $b_{i}$ coefficients are the stoichiometric ratios.

The Gibbs energy of the liquid phase are described by the substitutional model as follows:

$$
\begin{aligned}
G_{\mathrm{Linear}}^{\mathrm{Liq}}= & x_{\mathrm{P}} G_{\mathrm{P}}^{0, \mathrm{Liq}}+x_{\mathrm{Zn}} G_{\mathrm{Zn}}^{0, \mathrm{Liq}} \\
& +R T\left(x_{\mathrm{P}} \ln x_{\mathrm{P}}+x_{\mathrm{Zn}} \ln x_{\mathrm{Zn}}\right) \\
& +x_{\mathrm{P}} x_{\mathrm{Zn}}\left(L_{\mathrm{P}, \mathrm{Zn}}^{0, \mathrm{Liq}}+L_{\mathrm{P}, \mathrm{Zn}}^{1, \mathrm{Liq}}\left(x_{\mathrm{P}}-x_{\mathrm{Zn}}\right)\right)
\end{aligned}
$$

where $x_{\mathrm{P}}$ and $x_{\mathrm{Zn}}$ represent the mole fraction of elements $\mathrm{P}$ and $\mathrm{Zn}$ and $R$ is the gas constant $(R=8.3145 \mathrm{~J} / \mathrm{mol} \mathrm{K}) . L_{\mathrm{P}, \mathrm{Zn}}^{0, \mathrm{Liq}}$ and $L_{\mathrm{P}, \mathrm{Zn}}^{1, \mathrm{Liq}}$ are parameters representing the interaction between components $\mathrm{P}$ and $\mathrm{Zn}$ in the liquid phase. In the present work, we have used three descriptions for the binary interaction parameters: the subregular linear function, exponential model of Kaptay [15] and LET model [16].

Description 1: Linear model

$L_{\mathrm{P}, \mathrm{Zn}}^{i, \mathrm{Liq}}=a_{i}+b_{i} T$

where $a_{i}$ and $b_{i}$ are the enthalpy-like $(\mathrm{J} / \mathrm{mol})$ and the entropy-like $(\mathrm{J} / \mathrm{mol} \mathrm{K})$ semi-empirical coefficients of the $i$ th interaction parameter.
Description 2: Exponential model of Kaptay

$L_{\mathrm{P}, \mathrm{Zn}}^{i, \mathrm{Liq}}=h_{i}^{\mathrm{Liq}} \cdot \exp \left(-\frac{T}{\tau_{i}^{\mathrm{Liq}}}\right)$

where $h_{i}^{\mathrm{Liq}}$ and $\tau_{i}^{\mathrm{Liq}}$ are semi-empirical parameters; the former being the enthalpy part and the latter is a temperature (in $\mathrm{K}$ and must be positive) at which the interaction parameter changes its sign if it was extrapolated linearly.

Description 3: LET model

$L_{\mathrm{P}, \mathrm{Zn}}^{i, \mathrm{Liq}}=\left(a_{i}+b_{i} T\right) \cdot E(T)$

where $E(T)$ is:

$E(T)=\exp \left[-\left(\frac{T-T_{1}}{\sqrt{2} \cdot T_{2}}\right)^{2}\right]$

where $T_{1}$ and $T_{2}$ are two constant temperatures which are generally suggested to be 500 and $2000 \mathrm{~K}$, respectively [16]. Thus, $E(T)$ is described as:

$E(T)=\exp \left[-\left(\frac{T-500}{\sqrt{2} \cdot 2000}\right)^{2}\right]$

\section{Supplementary material}

Supplementary material associated with this article can be found, in the online version, at doi:10.1016/j.mtla.2019.100301.

\section{References}

[1] G.M. Kimball, A.M. Müller, N.S. Lewis, H.A. Atwater, Photoluminescence-based measurements of the energy gap and diffusion length of $\mathrm{Zn}_{3} \mathrm{P}_{2}$, Appl. Phys. Lett. 95 (11) (2009) 112103, doi:10.1063/1.3225151.

[2] M.J. Pawlikowski, Band structure and properties of $\mathrm{Zn}_{3} \mathrm{P}_{2}$ - promising new infrared material, Infrared Phys. 21 (3) (1981) 181-187.

[3] F. Briones, F.-C. Wang, R.H. Bube, Pair transitions in $\mathrm{Zn}_{3} \mathrm{P}_{2}$, Appl. Phys. Lett. 39 (1981) 805.

[4] J. Misiewicz, Inter-band transitions in $\mathrm{Zn}_{3} \mathrm{P}_{2}$, J. Phys. Cond. Mat. 2 (1990) 2053.

[5] J.M. Pawlikowski, Absorption edge of $\mathrm{Zn}_{3} \mathrm{P}_{2}$, Phys. Rev. B 26 (8) (1982) 4711-4713.

[6] T. Suda, K. Kakishita, Epitaxial growth of zinc phosphide, J. Appl. Phys. 71 (6) (1992) 3039-3041, doi:10.1063/1.350989.

[7] J. Misiewicz, L. Bryja, K. Jezierski, J. Szatkowski, N. Mirowska, Z. Gumienny, E. Placzek-Popko, $\mathrm{Zn}_{3} \mathrm{P}_{2}$ - a new material for optoelectronic devices, Microelectron. J. 25 (5) (1994) xxiii-xxviii, doi:10.1016/0026-2692(94)90078-7.

[8] J.P. Bosco, G.M. Kimball, N.S. Lewis, H.A. Atwater, Pseudomorphic growth and strain relaxation of $\alpha-\mathrm{Zn}_{3} \mathrm{P}_{2}$ on $\mathrm{GaAs}(001)$ by molecular beam epitaxy, J. Cryst. Growth 363 (2013) 205-210, doi:10.1016/j.jcrysgro.2012.10.054.

[9] S. Jeon, J.P. Bosco, S.S. Wilson, S.J. Rozeveld, H. Kim, H.A. Atwater, Growth mechanism and electronic structure of $\mathrm{Zn}_{3} \mathrm{P}_{2}$ on the Ga-rich GaAs(001) surface, J. Phys. Chem. C 118 (24) (2014) 12717-12726, doi:10.1021/jp4127804.

[10] G.Z. Shen, Y. Bando, J.Q. Hu, D. Golberg, Single-crystalline trumpetlike zinc phosphide nanostructures, Appl. Phys. Lett. 88 (14) (2006) 143105, doi:10.1063/1.2192090.

[11] G. Shen, P.-C. Chen, Y. Bando, D. Golberg, C. Zhou, Single-crystalline and twinned $\mathrm{Zn}_{3} \mathrm{P}_{2}$ nanowires: Synthesis, characterization, and electronic properties, J. Phys. Chem. C 112 (42) (2008) 16405-16410, doi:10.1021/jp806334k.

[12] L. Kaufman, H. Bernstein, Computer Calculations of Phase Diagrams, Academic Press, New York, 1970.

[13] H. Tu, F. Yin, X. Su, Y. Liu, X. Wang, Experimental investigation and thermodynamic modeling of the Al-P-Zn ternary system, Calphad 33 (4) (2009) 755-760, doi:10.1016/j.calphad.2009.10.003.

[14] Y. Liu, B. Zhou, W. Lv, C. Wu, X. Su, J. Wang, Experimental investigation and thermodynamic assessment of the Zn-Si-P system, Surf. Coat. Technol. 306 (2016) 370 377, doi:10.1016/j.surfcoat.2016.01.016.

[15] G. Kaptay, A new equation for the temperature dependence of the excess Gibbs energy of solution phases, Calphad 28 (2) (2004) 115-124, doi:10.1016/j.calphad.2004.08.005.

[16] S.-M. Liang, P. Wang, R. Schmid-Fetzer, Inherently consistent temperature function for interaction parameters demonstrated for the $\mathrm{Mg}-\mathrm{Si}$ assessment, Calphad 54 (2016) 82-96, doi:10.1016/j.calphad.2016.06.003.

[17] C.W. Pistorius, J. Dark, J. Coetzer, G.J. Kruger, O. Kunze, High pressure phase relations and crystal structure determination for zinc phosphide, $\mathrm{Zn}_{3} \mathrm{P}_{2}$, and cadmium phosphide, $\mathrm{Cd}_{3} \mathrm{P}_{2}$, High Temp. High Press. 9 (1977) 471-482.

[18] M.V. Stackelberg, R. Paulus, Investigation of phosphides and arsenides of zinc and cadmium, the structure of $\mathrm{Zn}_{3} \mathrm{P}_{2}$, Z. Phys. Chem. 28 (1935) 427-460. In German.

[19] J. Hegyi, E.E. Loebner, E.W. Poor, J.G. White, Two crystal forms of $\mathrm{ZnP}_{2}$, J. Phys. Chem Solids 24 (1963) 333-337. 
[20] Y. Tanaka, Chemical reaction at high temperature and high pressure. Polymorphic transition of $\mathrm{ZnP}_{2}$ at high temperature and high pressure, Rev. Phys. Chem. Jpn. 38 (1969) 151-169.

[21] V.M. Trukhan, S.F. Marenkin, T.V. Shoukavaya, Compounds and solid solutions in the Zn-P, Zn-As, and Cd-As systems formed under high pressures and temperatures, Crystallogr. Rep. 59 (1) (2014) 53-59, doi:10.1134/S1063774514010180.

[22] A. Simon, H. Borrmann, H. Craubner, Crystal structure of ordered white phosphorus( $\beta$-P), Phosph. Sulfur Rel. Elem. 30 (1-2) (1987) 507-510.

[23] P. Villarsa, M. Berndt, K. Brandenburg, K. Cenzual, J. Daams, F. Hulliger, T. Massalski, H. Okamoto, K. Osaki, A. Prince, H. Putz, S. Iwata, The Pauling file, binaries edition, J. Alloys Cmpnd. 367 (2004) 293-297.

[24] N. Sirota, A. Antyukhov, E.M. Smolarenko, Thermodynamic properties of semiconducting compounds $\mathrm{ZnP}_{2}$ (monoclinic) and $\mathrm{Zn}_{3} \mathrm{P}_{2}$, Dokl. Akad. Nauk. BSSR 19 (1975) 1092-1094.

[25] R.C. Schoonmaker, A.R. Venkitaraman, P.K. Lee, The vaporization of zinc phosphide, J. Phys. Chem. 71 (8) (1967) 2676-2683, doi:10.1021/j100867a043.

[26] Y.A. Valov, T.N. Ushakova, Thermal dissociation of zinc phosphide, Zhurnal Obshchei Khimii 40 (3) (1970) 524-528. English translation.

[27] N. Karvelis, Thermochemical properties of zinc phosphide. 1. Determination of the heat of formation of zinc phosphide during its synthesis from Zinc dust and red Phosphorus, Vilniaus Univ. Mokslo Darb. Chem. 28 (1959a) 110-117.

[28] N. Karvelis, Thermochemical properties of zinc phosphide. 2. Determination of heat of hydrolysis zinc phosphide and calculation of its heat of formation, Vilniaus Univ. Mokslo Darb. Chem. 28 (1959b) 119-120. Russian.

[29] S.I. Volfkovich, G.M. Strongin, A Collection of Papers Prepared by the Institute of Fertilizers and Insecticides, Moscow, 1960, p. 167.

[30] S.A. Shchukarev, G. Grossman, M. Morozova, Zh. Obshch. Khim. 25 (1955) 633.

[31] A.S. Alikhanyan, A.V. Steblevskii, Y.K. Grinberg, S.F. Marenkin, G.G. Magomedgadzhiev, V.I. Gorgoraki, Sublimation of $\mathrm{ZnP}_{2}$, Izvest. Akad. Nauk. SSSR Neorganicheskie Materialy 14 (11) (1978) 1966-1970. English translation.

[32] V.B. Lazarev, Y.K. Grinberg, S.F. Marenkin, G.G. Magomedgadzhiev, S.K. Samiev, Tensimetric and investigation of deviation from stoichiometry in $\mathrm{Zn}_{3} \mathrm{P}_{2}$, Izvest. Akad. Nauk. SSSR Neorganicheskie Materialy 14 (11) (1978) 1961-1965. English translation.
[33] T.M. Shantsovoi, Author's Abstract of Candidate's Dissertation, Moscow (1976).

[34] Y.A. Ugai, O.Y. Gukov, E.P. Domashevskaya, L.A. Ozerov, Phase diagrams of $\mathrm{Zn}-\mathrm{Zn}_{3} \mathrm{P}_{2}$ and $\mathrm{Cd}-\mathrm{Cd}_{3} \mathrm{P}_{2}$ systems, Izvest. Akad. Nauk SSSR Neorganicheskie Materialy 4 (1968) 147-148. English translation.

[35] J. Berak, Z. Pruchnik, Phase equilibria in the zinc-cadmium-phosphorus system. Part 2: the zinc-phosphorus system, Roczn. Chem. 43 (1969) 1141-1146.

[36] M. Schneider, M. Krumnacker, Investigations of the phase diagram zinc-phosphorus, Neue Hütte 18 (1973) 715-718.

[37] J. Dutkiewlcz, The P-Zn (phosphorus-zinc) system, J. Phase Equilib. 12 (4) (1991) 435-438, doi:10.1007/bf02645963.

[38] M. John, K. Hein, E. Buhrig, Investigation of II-IV-V systems by the method of differential thermal analysis, Kristall Technik 14 (7) (1979) 841-848, doi:10.1002/crat.19790140711.

[39] V.P. Vasil'ev, J.-C. Gachon, Thermodynamic properties of InP, Inorg. Mater. 42 (11) (2006) 1171-1175.

[40] V.P. Vasil'ev, B. Legendre, V. Zlomanov, The critical analysis and mutual coherence of the thermodynamic data of the AIIIBV phases, Intermetallics 19 (2011) 1891-1901.

[41] A.U. Sheleg, N.P. Tikhanovich, T.I. Yakubenko, Thermodynamic properties and phase transitions of tetragonal zinc diphosphide in the temperature range 6-400 K, Dokl. Akad. Nauk. BSSR 26 (1982) 882-884.

[42] K. Bartkowski, G. Pompe, E. Hegenbarth, Specific heat of singlecrystalline $\mathrm{Cd}_{3} \mathrm{As}_{2}$, $\mathrm{Cd}_{3} \mathrm{P}_{2}$, and $\mathrm{Zn}_{3} \mathrm{P}_{2}$ at low temperatures, Phys. Stat. Sol. a 111 (2) (1989) 165-169, doi:10.1002/pssa.2211110243.

[43] B. Sundman, B. Jansson, J.O. Andersson, The thermo-calc databank system, Calphad 9 (2) (1985) 153-190, doi:10.1016/0364-5916(85)90021-5.

[44] J.O. Andersson, T. Helander, L. Höglund, P. Shi, B. Sundman, Thermo-calc \& DICTRA, computational tools for materials science, Calphad 26 (2) (2002) 273-312.

[45] S.L. Chen, S. Daniel, F. Zhang, Y.A. Chang, W.A. Oates, R. Schmid-Fetzer, On the calculation of multicomponent stable phase diagrams, J. Phase Equilib. 22 (4) (2001) 373-378, doi:10.1361/105497101770332910.

[46] G. Kaptay, The exponential excess Gibbs energy model revisited, Calphad 56 (2017) 169-184, doi:10.1016/j.calphad.2017.01.002.

[47] SGTE unary database ver. 4.4, Updated from: A. T. Dinsdale, Calphad 15, 1991,317. 